\title{
OPTIMUM EFFICIENT MOBILITY MANAGEMENT SCHEME FOR IPv6
}

\author{
Virender Kumar \\ Department of Electronics \& Communication Engineering, HCTM Technical Campus, \\ Kaithal, India \\ gangotrahctmegmail. com
}

\begin{abstract}
Mobile IPv6 (MIPv6) and Hierarchical Mobile IPv6 (HMIPv6) both are the mobility management solutions proposed by the Internet Engineering Task Force (IETF) to support IP Mobility. It's been an important issue, that upon certain condition, out of MIPv6 and HMIPv6 which one is better. In this paper an Optimum Efficient Mobility Management (OEMM) scheme is described on the basis of analytical model which shows that OEMM Scheme is better in terms of performance and applicability of MIPv6 and HMIPv6. It shows that which one is better alternative between MIPv6 and HMIPv6 and if HMIPv6 is adopted it chooses the best Mobility Anchor Point (MAP). Finally it is illustrated that OEMM scheme is better than that of MIPv6 and HMIPv6.
\end{abstract}

\section{KEYWORDS}

Mobile IPv6; Hierarchical Mobile IPv6; Access Router; Regional Size; Mobility Anchor Point.

\section{INTRODUCTION}

With the fast increasing demand for the seamless mobility providers motivate to support seamless connectivity to Mobile Nodes (MNs). To complete this aim, Internet Engineering Task Force (IETF) proposed Mobile IP (MIP) protocol. MIPv4 and MIPv6 both are the mobility management solution to maintain the on-going communication when one MN moves from one subnet to another. MIPv6 become the next generation solution due to its several advantages over MIPv4. HMIPv6 is another scheme which gives the several advantages over MIPv6. Although HMIPv6 is the modification of the MIPv6 yet it can not outperform MIPv6 in all scenarios.

\section{BACKGROUND}

\subsection{Mobile IPv6(MIPv6)}

In Mobile IPv6 one MN is identified by two addresses: Home address and Care of address (CoA) [1]. Home Address represents the permanent address of MN and Care of Address (CoA) is the Temporary Address, representing the current location of MN. There is a mobility management entity i.e. Home Agent (HA) which stores the binding information of the MN. Home Agent also receives all the packets on behalf of the $\mathrm{MN}$ when the Correspondent Nodes do not know the current location of the MN. In MIPv6 there is a process known as "Home Registration" in which updated location is registered in HA when the MN roams in the visited networks. But in MIPv6 a frequent handover by $\mathrm{MN}$ in a local region leads to a longer signaling delay. In Handover process this longer signaling delay is the main problem of the MIPv6.

DOI : 10.5121/ijngn.2012.4305 


\title{
2.2 Hierarchical Mobile IPv6 (HMIPv6)
}

To solve this problem, Hierarchical Mobile IPv6 (HMIPv6) is introduced. In HMIPv6 [2] a new entity is introduced known as Mobility Anchor Point (MAP) to act as a local Home Agent with in a region. In HMIPv6 Mobility Anchor Point (MAP) have a number of Access Routers (ARs). The number of ARs under a MAP is known as the Regional Size. In HMIPv6, there are two addresses: Regional care of address (RCoA) representing the MN's MAP \& the on-Link CoA (LCoA) representing the AR that the MN attaches to.There are two types of mobility in HMIPv6: micromobility (handover with in a region) and macro-mobility (handover across the regions). In macromobility, the MN gets two new addresses: RCoA, LCoA and it will initiate a regional registration process to bind these two addresses. After having successful regional registration, the $\mathrm{MN}$ gives its new update of having new RCoA to it's HA i.e. there is a binding between its Home Address and RCoA to the HA by a Home Registration. In micro-mobility there is only a regional registration because there is no new RCoA of a MN within a region. Now, we see that in HMIPv6 when $\mathrm{MN}$ roams from one region to another, there is a double registration: regional registration and home registration. So in HMIPv6 the handover latency is smaller than that of MIPv6 when the MNs roam within the region but the handover latency is larger than that of MIPv6 when the MNs roam inter- region. Besides, in double registration there is a MAP processing delay leading to a longer packet delivery time because all the packets destined to MN are tunneled through MAP. So, Double registration leads to a larger handover latency and longer packet delivery time. So it is an interesting issue to select to find out the performance of MIPv6 and HMIPv6 depending upon certain conditions.

\section{Performance Analysis Of Mipv6 And Hmipv6}

\subsection{Relative Registration Cost [3]}

Definition 1: (Relative Registration Cost): Relative registration cost $\left(T_{R}\right)$ is defined as the average registration time saved by using HMIPv6 compared with MIPv6 [3]

$T_{R}$ may be positive or negative. $T_{R}>0$ means the average registration delay of MIPv6 is shorter than that of HMIPv6, otherwise longer.

\section{MAIN SYMBOLS IN REGISTRATION PERFORMANCE ANALYSES}

\author{
Symbols Definitions \\ $\mathrm{T}_{\mathrm{R}} \quad$ Average registration delay of MIPv6 \\ $\mathrm{T}_{\mathrm{AM}} \quad$ Average delay of delivering registration signaling over wireless link between $\mathrm{AR}$ \\ and MN \\ $\mathrm{T}_{\mathrm{HA}} \quad$ Average delay of delivering registration signaling between $\mathrm{HA}$ and $\mathrm{AR}$ \\ $\mathrm{T}_{\mathrm{H}} \quad$ Average registration signal processing latency of HA \\ $\mathrm{T}_{\text {intra }} \quad$ Average delay of a registration process in HMIPv6 during an intra-MAP handover \\ $\mathrm{T}_{\text {inter }} \quad$ Average delay of a registration process in HMIPv6 during an inter-MAP handover \\ $\mathrm{T}_{\mathrm{MA}} \quad$ Average delay of delivering registration signaling between MAP and AR \\ $l_{\mathrm{MA}} \quad$ Average distance between MAP and its reachable ARs \\ $1_{\mathrm{HA}} \quad$ Average distance between HA and AR \\ $\mathrm{T} \quad$ Average dwell time that an MN stays in an AR \\ $\mu \quad$ Unit distance signaling transmission cost of wired link
}

According to RFC3775[1] and RFC4140 [2] in MIPv6 there is only home registration but in HMIPv6 there are to registrations: regional registration and home registration. Hence, $T_{R M}, T_{\text {intra }}$ and $\mathrm{T}_{\text {inter }}$ can be calculated as: 


$$
\begin{aligned}
& \mathrm{T}_{\mathrm{RM}}=2 \mathrm{~T}_{\mathrm{AM}}+2 \mathrm{~T}_{\mathrm{HA}}+\mathrm{T}_{\mathrm{H}} \\
& \mathrm{T}_{\text {intra }}=2 \mathrm{~T}_{\mathrm{AM}}+2 \mathrm{~T}_{\mathrm{MA}}+\mathrm{T}_{\mathrm{M}} \\
& \mathrm{T}_{\text {inter }}=4 \mathrm{~T}_{\mathrm{AM}}+2 \mathrm{~T}_{\mathrm{MA}}+2 \mathrm{~T}_{\mathrm{HA}}+\mathrm{T}_{\mathrm{H}}+\mathrm{T}_{\mathrm{M}}
\end{aligned}
$$

Let the MN needs $\mathrm{m}^{\text {th }}$ handover to move out of a region $(\mathrm{m} \geq 1)$.Then, in new region the $\mathrm{MN}$ will enter at its $\mathrm{m}^{\text {th }}$ handover. So the total average delay $\left(\mathrm{T}_{\mathrm{IT}}\right)$ that an $\mathrm{MN}$ spends for $\mathrm{m}$ handovers in HMIPv6 and MIPv6 is [3]

$\mathrm{T}_{\mathrm{IT}}=(\mathrm{m}-1) \mathrm{T}_{\text {intra }}+\mathrm{T}_{\text {inter }}$

$\mathrm{T}_{\mathrm{AT}}=\mathrm{mT}_{\mathrm{RM}}$

Using definition 1 and equations (4) \& (5), $\mathrm{T}_{\mathrm{R}}$, can be calculated as

$$
\mathrm{T}_{\mathrm{R}}=\frac{\mu\left(2 \theta+2 \mathrm{~m} 1_{\mathrm{MA}}-21_{\mathrm{HA}}(\mathrm{m}-1)+\mathrm{m}\left(\mathrm{T}_{\mathrm{M}}-\mathrm{T}_{\mathrm{H}}\right)+\mathrm{T}_{\mathrm{H}}\right)}{\mathrm{m} \mathrm{T}}
$$

Where $\mu$ is unit distance signaling transmission cost of of wired link. We also suppose the average signaling delivering delay of wireless link be $\theta . \mu$, where $\theta>1$. From formulae (6) we can say that if the nearer the distance between MN and MAP and the farther the distance between HA and $\mathrm{MN}$, then HMIPv6 gives higher average registration revenue. i.e. Only when, $\mathrm{T}_{\mathrm{R}}<0$, HMIPv6 obtains the average registration revenue. Two theorems can be deduced.

Theorem 1: HMIPv6 outperforms MIPv6 in terms of registration revenue when an MN roams within a region (intra-region) and the average registration revenue is $\mid 2 \mu .\left(l_{\mathrm{MA}}-l_{\mathrm{HA}}\right) / \mathrm{T}$ I. In micromobility $\mathrm{T}_{\mathrm{R}}$ can be calculated as [4]

$$
\mathrm{T}_{\mathrm{R}}=\frac{2 \mu\left(l_{M A}-l_{H A}\right)+T_{M}-T_{H}}{T}
$$

Theorem 2: $\mathrm{T}_{\mathrm{R}}$ lies on the regional size, $\mathrm{K}$, when the $\mathrm{MN}$ roams across different regions (interregion). In this $T_{R}$ can be calculated as on certain conditions as [4]:

$$
\begin{gathered}
T_{R}=\frac{\left(2 \mu \cdot \theta+T_{H}\right) \cdot(2 N-2 K-1)+2 \mu \cdot l_{H A} \cdot(1-2 K)}{(2 N-2) \cdot T} \\
+\frac{4 \mu \cdot(N-1) \cdot l_{M A}+2(N-1) \cdot\left(T_{M}-T_{H}\right)}{(2 N-2) \cdot T}
\end{gathered}
$$

\subsection{Relative Packet Delivery Cost [3]}

Definition 2: (Relative Packet Delivery Cost): Relative packet delivery cost $\left(D_{P}\right)[3]$ is defined as the average time wasted by using HMIPv6 instead of MIPv6 to forward packets.

\section{MAIN SYMBOLS IN PACKET DELIVERY PERFORMANCE ANALYSES}

Symbols

$\mathrm{D}_{\mathrm{PM}}$

$\alpha$.
Definitions

Average packet delivery delay of MIPv6

Average packet arrival rate 


$$
\begin{aligned}
& \mathrm{D}_{\mathrm{H}} \\
& \mathrm{D}_{\mathrm{CH}} \\
& \mathrm{D}_{\mathrm{HA}} \\
& \mathrm{D}_{\mathrm{AM}} \\
& \mathrm{D}_{\mathrm{PH}} \\
& \mathrm{D}_{\mathrm{M}} \\
& \mathrm{D}_{\mathrm{HM}} \\
& 1_{\mathrm{HM}}
\end{aligned}
$$

Average packet processing latency of HA

Average delay of forwarding packets from $\mathrm{CN}$ to $\mathrm{HA}$ Average delay of forwarding packets from HA to AR Average delay of forwarding packets from AR to MN Average packet delivery delay of HMIPv6 Average packet processing delay of MAP Average delay of forwarding packets from HA to MAP Average distance between HA and MA

According to [1] and [2], the average latency of forwarding packets from a $\mathrm{CN}$ to the $\mathrm{MN}$ in MIPv6 and HMIPv6 are

$\mathrm{D}_{\mathrm{PM}}=\alpha \cdot\left(\mathrm{D}_{\mathrm{H}}+\mathrm{D}_{\mathrm{CH}}+\mathrm{D}_{\mathrm{HA}}+\mathrm{D}_{\mathrm{AM}}\right)$

$\mathrm{D}_{\mathrm{PH}}=\alpha \cdot\left(\mathrm{D}_{\mathrm{H}}+\mathrm{D}_{\mathrm{M}}+\mathrm{D}_{\mathrm{CH}}+\mathrm{D}_{\mathrm{HM}}+\mathrm{D}_{\mathrm{MA}}+\mathrm{D}_{\mathrm{AM}}\right)$

According to definition 2, the average packet delivery cost is given by

$D_{P}=D_{P H}-D_{P M}=\alpha \cdot\left(D_{M}+D_{H M}+D_{M A}-D_{H A}\right)$

We assume that $\delta$ is the average delay of encapsulating a packet in MAP, so $\mathrm{D}_{\mathrm{M}}$ can be calculated as:

$\mathrm{D}_{\mathrm{M}}=\mathrm{A} \cdot \mathrm{wK}+\mathrm{B} \cdot \lg \cdot \mathrm{K}+\delta$

Where A and B are positive coefficients

Assume that the average packet delivery delay of wired link is proportional to the number of hops that the packets travel with the proportionality constant $\eta$. Then Equation becomes [4]

$\mathrm{D}_{\mathrm{P}}=\alpha \cdot\left(\mathrm{A} \cdot \mathrm{wK}+\mathrm{B} \cdot \lg \cdot \mathrm{K}+\delta+\eta \cdot\left(\mathrm{l}_{\mathrm{HM}}+\mathrm{l}_{\mathrm{MA}}-\mathrm{l}_{\mathrm{HA}}\right)\right)$

Where $\alpha$ is average packet arrival time, $\delta$ is the average delay of encapsulating a packet in MAP, $\mathrm{A} \& \mathrm{~B}$ are coefficients, w.k is the average no. ARs in a region with assuming that an AR can serve $w$ MNs on average and $l g$ is the logarithmic function.

Equation (13) leads to the conclusion that average packet delivery cost is positive on certain condition [4]. When $D_{P}>0$, it means average packet delivery delay of HMIPv6 is longer than that of MIPv6.

\subsection{Relative Cost [3]}

Definition 3: (Total Cost Function): Total cost function denoted as $\mathrm{C}_{\mathrm{T}}$ gives the overall performance of HMIPv6 against MIPv6 in terms of registration and packet delivery cost [3].

$$
\mathrm{C}_{\mathrm{T}}=\mathrm{n}_{1} \cdot \mathrm{T}_{\mathrm{R}}+\mathrm{n}_{2} \cdot \mathrm{D}_{\mathrm{P}}
$$

Where $\mathrm{n}_{1}>0$ and $\mathrm{n}_{2}>0$ are the coefficients.

As per the eq. (14), when $C_{T}>0$, MIPv6 will be more applicable than HMIPv6 otherwise HMIPv6 is adopted. 


\subsection{The IMS Scheme [4]}

When regional size K increases, HMIPv6 may gain more average registration revenue while paying more average packet delivery cost. However, $\mathrm{K}$ cannot increase indefinitely due to the processing bottleneck of the MAP [7]. The total average packet processing latency of the MAP is given by $\alpha \cdot(\mathrm{A} . w \mathrm{~K}+\mathrm{B} \cdot \lg \cdot \mathrm{K}+\delta)$, which depends on its load. Thus, a proper $\mathrm{K}$ that minimizes $\mathrm{C}_{\mathrm{T}}$ will optimize the overall performance of HMIPv6 against MIPv6. Denote such $\mathrm{K}$ as $\mathrm{K}_{\mathrm{opt}}$, which can be solved as follows [4]

$\min \mathrm{C}_{\mathrm{T}}(\mathrm{K})$

$\alpha \cdot($ A.wK + B.lg $\mathrm{K}+\delta)<\psi$

Where $\psi$ is a constant restricting the total packet processing latency of the MAP.

Definition 4: Cost function of HMIPv6: called $\mathrm{C}_{\mathrm{HMIPv}}$ formulates the absolute performance of HMIPv6 in terms of the average registration and packet delivery delay. It is given by

$$
\mathrm{C}_{\text {HMIPv }}=\mathrm{n}_{1} \cdot \frac{(\mathrm{m}-1) \mathrm{T}_{\text {intra }}+\mathrm{T}_{\text {inter }}}{\mathrm{mT}}+\mathrm{n}_{2} \cdot \mathrm{D}_{\mathrm{PH}}
$$

Where $\mathrm{n}_{1}$ and $\mathrm{n}_{2}$ are the same as in Definition 3 .

\section{THE OEMM SCHEME}

In this section we propose an Optimum Efficient Mobility Management (OEMM) scheme in which Firstly; we employ an algorithm to evaluate the performance of MIPv6 and HMIPv6 against some key parameters using an analytical model. The algorithm of the impact of parameters on the applicability of MIPv6 and HMIPv6 has been described in this section. Secondly, we employ an algorithm which shows that how cost changes with $\alpha$ and T.

\subsection{Algorithm for the performance of MIPv6 \& HMIPv6 against Key parameters}

1. Enter the $x$ different values of Regional Size $(K)$ and a fixed number of Access Routers N.

2. Enter the fixed values of $\mathrm{T}, \alpha$ and $\mathrm{l}_{\mathrm{MA}}$

3. For $(\mathrm{i}=1$ to $\mathrm{x})$

IF (Regional size [i] $\geq \mathrm{N}$ (no. of different access routers)

Compute $\mathrm{T}_{\mathrm{R}}$ according to eq. (7).

Compute $\mathrm{D}_{\mathrm{P}}$ according to eq. (13).

Compute $\mathrm{C}_{\mathrm{T}}$ according to eq. (14).

Plot a graph between $\mathrm{C}_{\mathrm{T}}$ and Regional size

ELSE

Compute $\mathrm{T}_{\mathrm{R}}$ according to eq. (8).

Compute $\mathrm{D}_{\mathrm{P}}$ according to eq. (13).

Compute $\mathrm{C}_{\mathrm{T}}$ according to eq. (14).

Plot a graph between $\mathrm{C}_{\mathrm{T}}$ and Regional size

4. Change $\mathrm{T}$ to see the impact of $\mathrm{T}$ on $\mathrm{C}_{\mathrm{T}}$ for a fixed value of regional size and go to step 3 .

5. Change $\alpha$ to see the impact of $\alpha$ on $\mathrm{C}_{\mathrm{T}}$ for a fixed value of regional size and go to step 3 .

6. Change $1_{\mathrm{MA}}$ to see the impact of $\mathrm{l}_{\mathrm{MA}}$ on $\mathrm{C}_{\mathrm{T}}$ for a fixed value of regional size and go to step (3).

7. Exit. 
International Journal of Next-Generation Networks (IJNGN) Vol.4, No.3,September 2012

\subsection{Algorithm for the performance of MIPv6 \& HMIPv6 to show cost changes with $\alpha$ and $T$}

1. Start

2. Input the value of $\mathrm{OC}, \mathrm{M} \&$ all parameters.

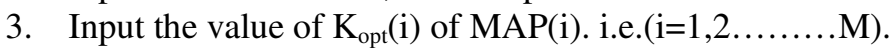

4. If $\mathrm{MN}$ gets the information about parameters on handover.

5. Check for $\alpha, T$ or MAP.

6. If $\alpha, \mathrm{T}, \mathrm{MAP}$ changes then go to step 7, otherwise go to step 13 .

7. Calculate $\mathrm{C}_{\mathrm{t}}(\mathrm{i})$ of MAP (i) i.e. $(\mathrm{i}=1,2 \ldots \ldots \ldots \mathrm{M})$.

8. $\mathrm{OC}=\operatorname{Min} .\left\{\mathrm{C}_{\mathrm{t}}(\mathrm{i})\right\}$ i.e. $(\mathrm{i}=1,2 \ldots \ldots \ldots \mathrm{M})$.

9. $\mathrm{OK}_{\mathrm{opt}}=\mathrm{K} \operatorname{Arg} \min .\left\{\mathrm{C}_{\mathrm{t}}(\mathrm{i})\right\}$ i.e. $(\mathrm{i}=1,2 \ldots \ldots \ldots \mathrm{M})$.

10. If $\mathrm{OC} \geq 0$, then $\mathrm{MN}$ adopts MIPv6.

11. Else, OC $<0$, then MN adopts HMIPv6 and MN chooses the MAP whose sequence no. is OC.

12 The chosen MAP regional size $\mathrm{OK}_{\mathrm{opt}}$

13 There is no information about Handover (MN will stay in same AR).

14 END 


\subsection{Flowchart for OEMM scheme}

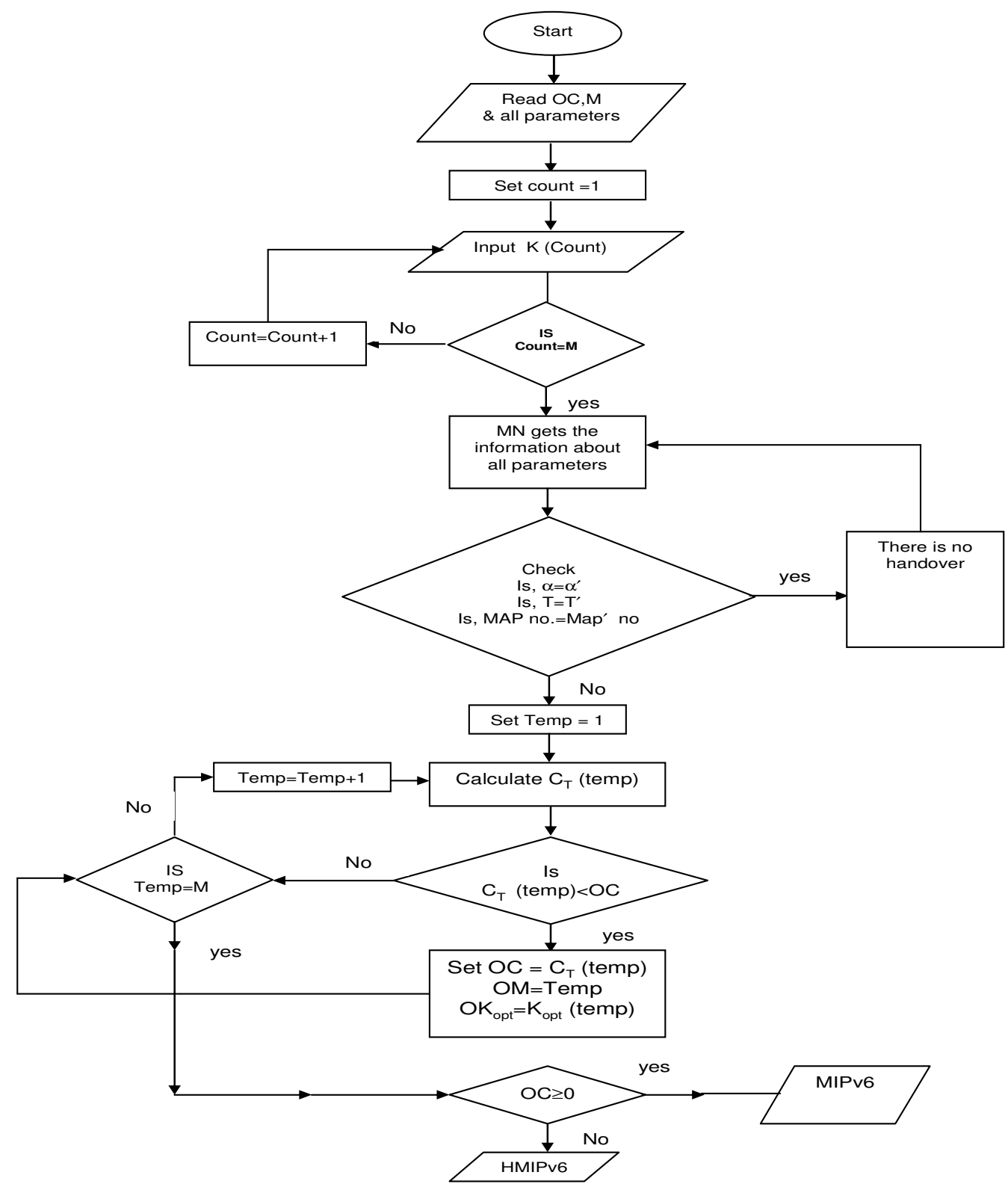

Choose MAP whose

sequence no. is OM \& its

regional size is $\mathrm{OK}_{(\mathrm{opt})}$

\section{Numerical Results ANd Discussion}

In this section, we demonstrate the performance of MIPv6 and HMIPv6 against some key parameters. We employ numerical analysis to show the results. The parameters used in the simulation process are taken from the various existing literature. The estimating value of $\alpha$ can be found in $[7,8]$ while $T$ can be computed by the method introduced in [6]. In addition the value of $w$ and $N$ are from [10]. The estimating value of $\mathrm{l}_{\mathrm{HM}}$ and $\mathrm{l}_{\mathrm{MA}}$ are taken from [9]. 


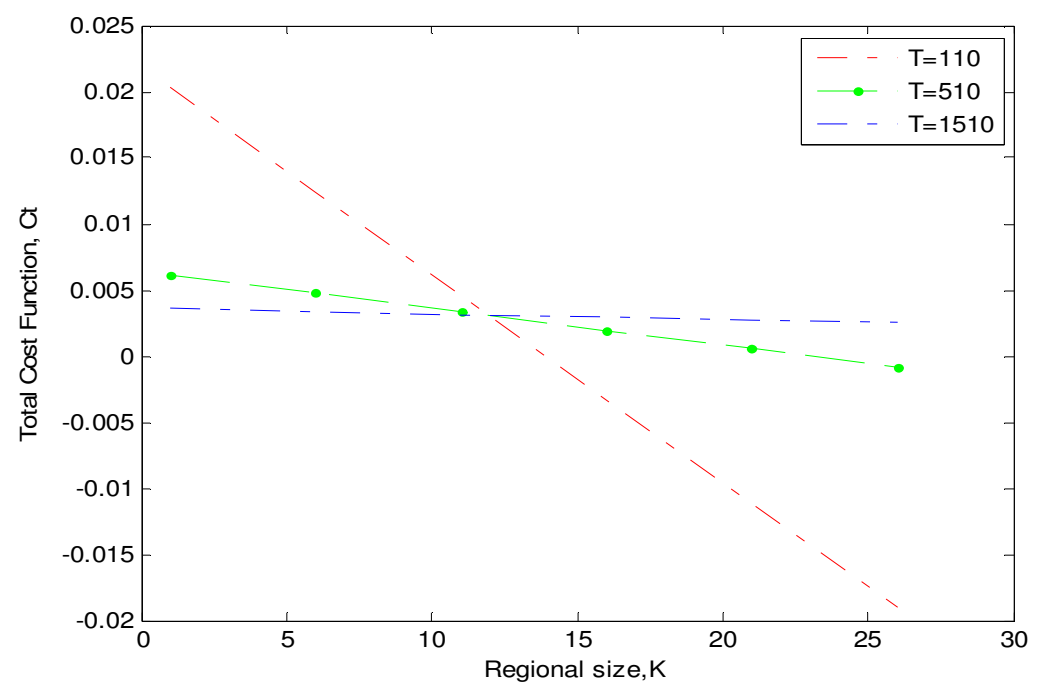

Figure.1 Impact of $\mathrm{T}$ on $\mathrm{C}_{\mathrm{T}}$

In figure 1 impact of $T$ on $C_{T}$ has been shown. In this case the values of $1_{\mathrm{MA}}=7$ and $\alpha=.06$. In this figure we see that for $\mathrm{K} \leq 13, \mathrm{C}_{\mathrm{T}}$ is greater than 0 and increases with the decreasing of $\mathrm{T}$.

In figure 2 the impact of $\alpha$ on $\mathrm{C}_{\mathrm{T}}$ has been shown. In this case the values of $\mathrm{l}_{\mathrm{MA}}=7$ and $\mathrm{T}=110$. Since as $\alpha$ increases the average packet delivery cost is increased which leads to increase in $C_{\mathrm{T}}$.

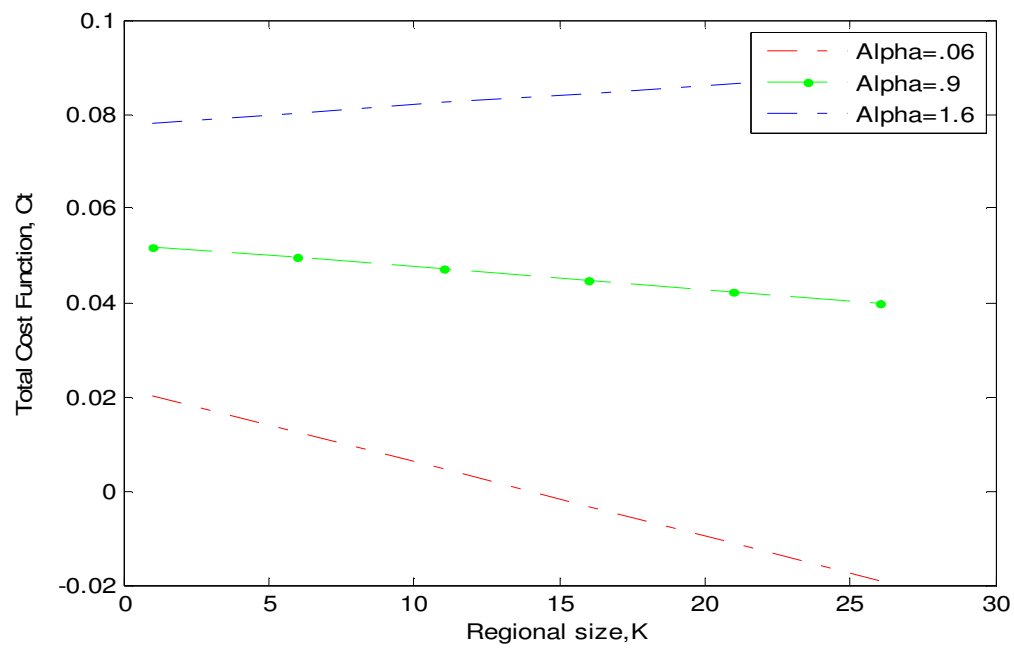

Figure 2. Impact of $\alpha$ on $\mathrm{C}_{\mathrm{T}}$

Figure 3 shows the impact of the distance $\left(l_{\mathrm{MA}}\right)$ between $\mathrm{AR}$ and MAP on $\mathrm{C}_{\mathrm{T}}$. In this case the values of $\mathrm{T}=110$ and $\alpha=.06$ is taken. In this figure we see that as $\mathrm{l}_{\mathrm{MA}}$ is increased, the $\mathrm{C}_{\mathrm{T}}$ is also increased. This is due to the fact that both average packet delivery delay and the average registration delay is increased in HMIPv6 when the distance $1_{\mathrm{MA}}$ increases, leading in the increase in $\mathrm{C}_{\mathrm{T}}$. 
The comparison of the performance of OEMM, HMIPv6 (the regional size is 7 or 13) and MIPv6 in figures 4 and 5 using cost as the metric. The cost of the OEMM is taken from the formula (16). Figures $4 \& 5$ shows that how cost changes with the changing of $\alpha$ and T. We also observe that the cost of OEMM is minimum w.r.t.MIPv6 and HMIPv6.

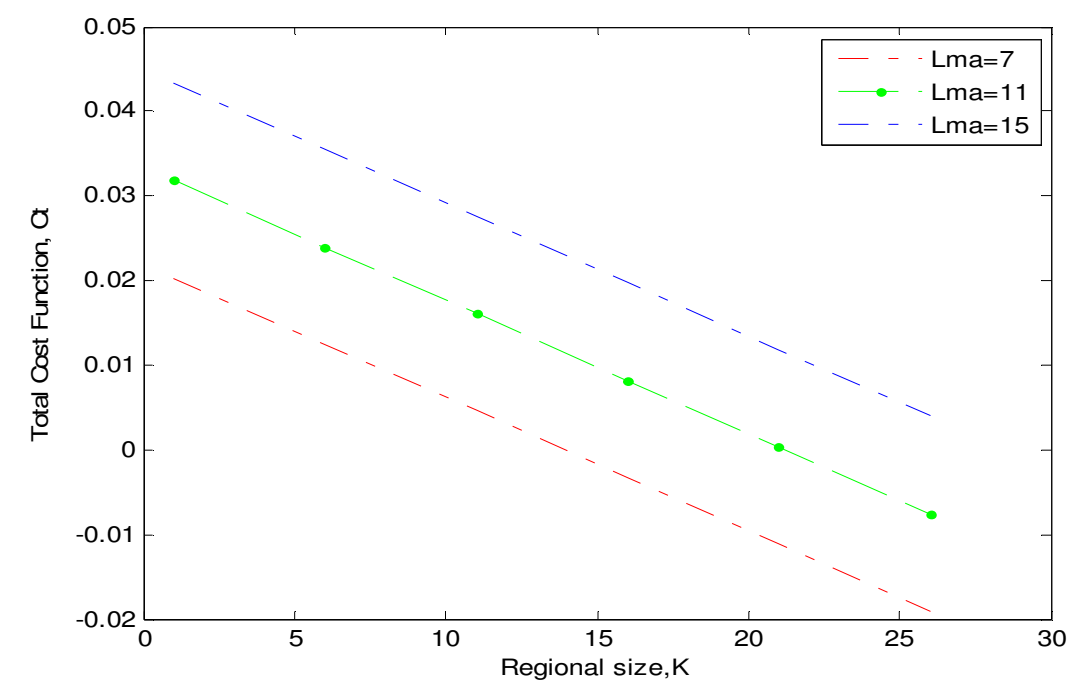

Figure 3. Impact of $\mathrm{l}_{\mathrm{MA}}$ on $\mathrm{C}_{\mathrm{T}}$

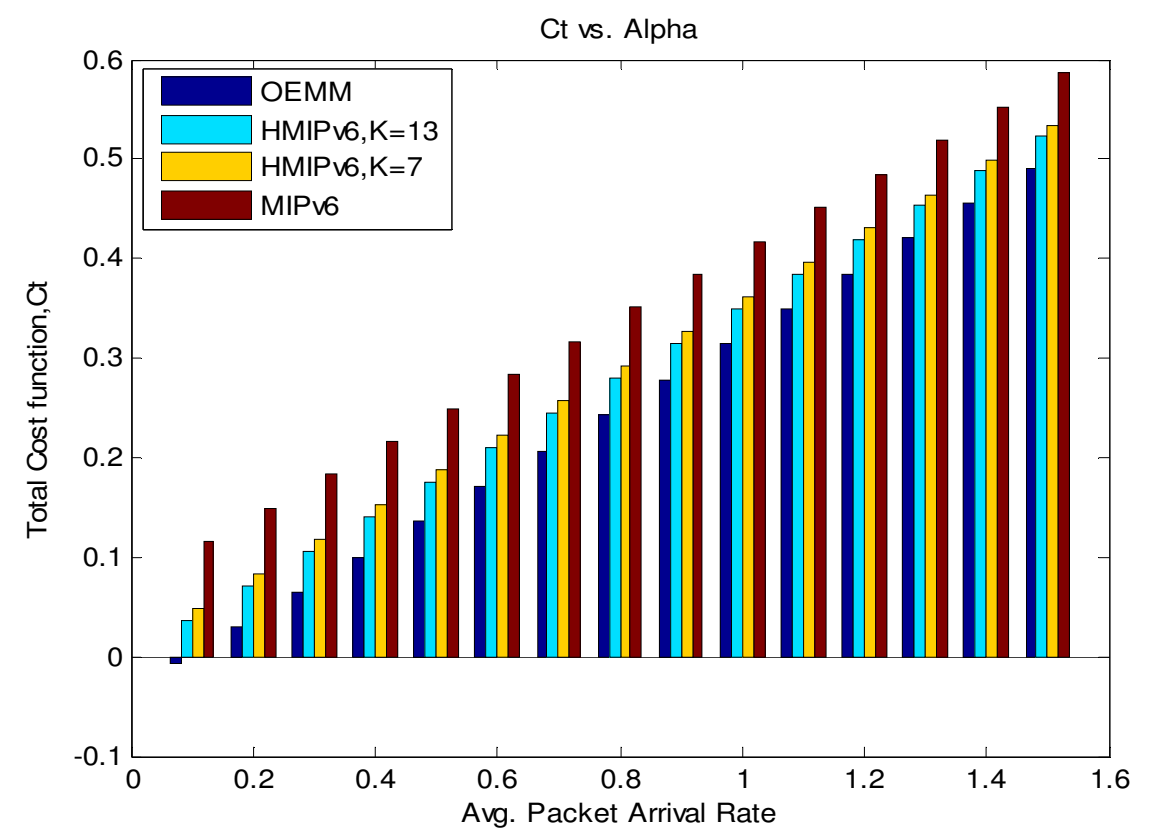

Figure 4. Cost vs. $\alpha$ 


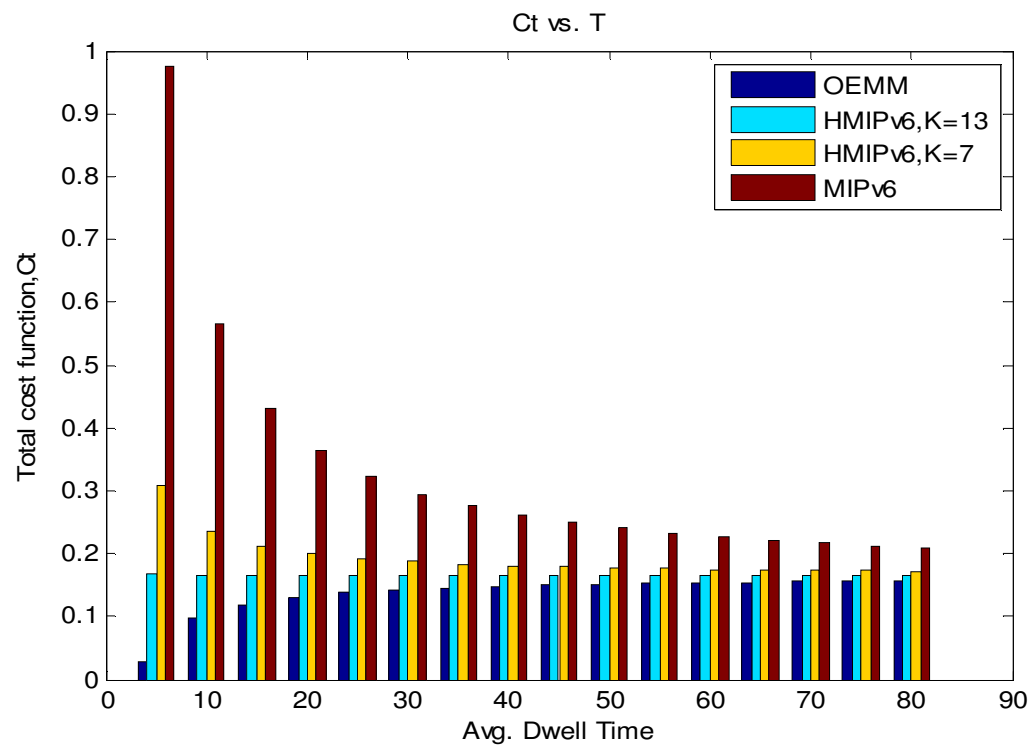

Figure 5. Cost vs. T

\section{Conclusion}

In this paper we evaluated a performance of MIPv6 and HMIPv6 in the form of impact of certain parameters on the total cost function. It is also evaluated that OEMM scheme shows the minimum cost when it is compared with MIPv6 and HMIPv6. Finally, the performance of MIPv6 and HMIPv6 has been simulated in this paper.

\section{REFERENCES}

[1] D. Johnson, C. Perkins, and J. Arkko, "Mobility Support in IPv6," RFC3775, June 2004.

[2] H. Soliman, C. Castelluccia, K. El Malki, and L. Bellier, "Hierarchical Mobile IPv6 Mobility Management (HMIPv6)," RFC4140, 2005.

[3] Shengling Wang, Yong Cui, Sajal K. Das, Wei Li, and Jianping Wu, "Mobility in IPv6: Whether and How to Hierarchize the Network?" 1045-9219/11/\$26.00 , 2011 IEEE

[4] Shengling Wang, Yong Cui, Sajal K.Das "Intelligent Mobility support for IPv6". 978-1- 4244-24139/08/\$25.00 @2008 IEEE

[5] H. Tzeng and T. Przygienda. "On Fast Address-Lookup Algorithms". IEEE J. Selected Areas in Communications, vol. 17, no. 6, pp. 1067-1082, 1999.

[6] Y. Chen and M. Huang. "A Novel MAP Selection Scheme by Using Abstraction Node in Hierarchical MIPv6”. Proc. IEEE International Conference on Communications, 2006. pp:5408-5413

[7] H. Xie, S. Tabbane, and D.J. Goodman. "Dynamic Location Area Management and Performance Analysis". Proc. 43 ${ }^{\text {rd }}$ IEEE Vehicular Technology Conference, 1993. pp:536-539

[8] M. Yabusaki. "Mobility/Traffic Adaptive Location Management". Proc. IEEE 56th Vehicular Technology Conference, Vancouver, 2002. pp:1011-1015

[9] W.R. Stevens, TCP/IP Illustrated, Volume 1: The Protocols. Addison Wesley Longman, Inc., 1994.

[10] J Xie. and I.F.Akyildiz. "A Novel Distributed Dynamic Location Management Scheme for Minimizing Signaling Costs in Mobile IP”. IEEE Transactions on Mobile Computing, vol. 1, no. 3, pp.163-175,2002. 